\title{
EAl Endorsed Transactions

\section{Review on the Role of Macular Edema in Retinopathy, Blindness and Automated Diagnosis Methods}

\author{
M. J. Barman ${ }^{1}$, D. Deb ${ }^{1}$, M.K. Hassan ${ }^{1}$, and B. Choudhury ${ }^{1, *}$ \\ ${ }^{1}$ Department of Computer Science and Engineering, Assam down town University, Guwahati, India
}

\begin{abstract}
INTRODUCTION: Macular edema is not a disease itself, but, a very common condition in most of the retinal diseases, such as diabetic retinopathy, retinal vein occlusion, hypertensive retinopathy, age-related macular edema, etc. and postocular surgery.

OBJECTIVES: We have discussed how macular edema plays an important role in blindness in case of various retinal blood vascular diseases and post-ophthalmic surgery. We have analyzed vast state-of-the-art methods for retinal abnormality detection.

METHODS: The proposed method uses a semi-automated macula segmentation approach and Local Binary Pattern features to train k-Nearest Neighbor classifier and performs binary classification.

RESULTS: We have achieved $80 \%$ accuracy and $90 \%$ sensitivity in classifying normal and abnormal retina

CONCLUSION: We justified the notion that it will be beneficial to have a method that can analyse the macula region and alert if there is any abnormality near that region to prevent vision loss.
\end{abstract}

Keywords: Macula, Retinal Abnormality, Macular Edema, Cystoid Macular Edema, Blindness, Computer aided diagnosis.

Received on 09 November 2020, accepted on 08 March 2021, published on 17 March 2021

Copyright (C) 2021 M. J. Barman et al., licensed to EAI. This is an open access article distributed under the terms of the Creative Commons Attribution license, which permits unlimited use, distribution and reproduction in any medium so long as the original work is properly cited.

doi: 10.4108/eai.17-3-2021.169034

"Corresponding author. Email:bismi.choudhury@gmail.com

\section{Introduction}

The retina is the light-sensitive thin layer of cells lining up at the back of the eye. The centermost part of the retina is called macula. The macula is responsible for our central vision and therefore, it is the most sensitive area for sustaining the best visual acuity. Sometimes the layers of the macula region become swollen with fluid and this condition is termed as Macular Edema (ME) [1]. When fovea, the centre of macula, is involved the visual acuity decreases. If untreated, chronic macular edema can lead to irreversible damage to the macula and permanent vision loss. Macular edema, degeneration, small yellowish deposits or drusen, haemorrhage, hole, fibrosis, pucker, vitreomacular traction, and scar are some common conditions that affect the macula. Distorted vision, blank spot, and blurred vision are common symptoms of ME. However, it can be asymptomatic as well [1].

The key fact is that macular edema in and of itself is not a retinal disease but rather it progresses as a result of other eye problems or health issues [2]. There are several eye conditions or various diseases that can lead to macular edema. It is the most common cause of blindness in patients suffering from diabetic retinopathy (DR) [3] and in the variants of retinal vein occlusions (RVO) [4]. ME is also a chief cause of diminished vision following various intraocular surgery [5]. In the literature, the term cystoid macular edema (CME) is frequently used for describing edema occurring after surgery [6], since fluid developed in the macula often results in cystic changes that are visibly significant through ophthalmoscopy. However, cystic changes can ensue with any type of macular edema, and therefore, the term post-surgical macular edema is preferred while describing to edema occurring after any type of 
intraocular procedure. ME is also a common complication of uveitis regardless of etiology [7] and is frequently seen in the case of retinitis pigmentosa [8]. Thus, macular edema is a common factor of various pathological conditions and creates enormous clinical complications that lead to blindness. Some of the common causes are as follows:

- Diabetes: Diabetes can affect retinal blood vessel walls, causing them to weaken and leak out fluids inflicting damage to one's vision. One of the complications of diabetes is diabetic retinopathy, and it is the most common eye disease that leads to irreversible blindness. Diabetic retinopathy usually affects both eyes. Diabetic retinopathy is instigated by the continuous damage to the tiny blood vessels of the retina. The leakage of fluid from the blood vessels leads to swelling of the surrounding tissue, including the macula. This condition is known as Diabetic Macular Edema (DME), which is the most common cause of blindness in people with diabetic retinopathy [9]. The risk of vision loss in the patients with DME increases with poor blood sugar control and other medical conditions, such as high blood pressure. DME can occur at any stage of diabetic retinopathy, although it is more common in later stages of DR. The experts estimate that approximately 7.7 million Americans have diabetic retinopathy and of those, about 750,000 also have DME [10].

- Age-related macular degeneration: Age-related macular degeneration (AMD) is a retinal disease characterized by deterioration of the macula. In the wet form of age-related macular degeneration, termed neovascular AMD, where fragile blood vessels grow up from the choroid layer of the retina. The fluid leaking out of them causes the macula region to swell and form macular edema. The Centers for Disease Control and Prevention has estimated that around 1.8 million people have AMD and another 7.3 million are at substantial risk for vision loss from AMD [11].

- Eye Surgery: Apart from various eye diseases, ME can also develop after any type of ophthalmic surgery such as surgery for glaucoma, cataract, or other retinal diseases. The experts estimate $1-3 \%$ of people who have undergone cataract surgery may develop ME within a few weeks after surgery. If one eye gets affected, there is a $50 \%$ chance that the other eye will also be affected. ME after eye surgery is generally mild, short-lasting, and responds well to medications like eye drops that treat inflammation [12].

- Blockage in the retinal vein: The blood vessels of the retina sometimes get blocked, known as retinal vein occlusion (RVO), due to various health conditions. Due to the blockage in veins, blood is unable to drain and then, excess fluid leaks into the retina. If it leaks into the macula, it forms macular edema. Leakage is exacerbated by the severity of the blockage, how many veins are involved, and the pressure inside them. RVO is most often associated with diabetes, high blood pressure, age-related atherosclerosis, and eye conditions such as glaucoma or inflammation [13].

- Inflammatory Eye Diseases: Uveitis, toxoplasmosis, and sarcoidosis are related to inflammation and can lead to swelling in the macula. Uveitis defines a group of inflammatory diseases inimical to eye tissues that cause swelling in the eye. Apart from the inflammatory diseases, the immune system disorders may also affect the eye and cause swelling and breakdown of macular tissue. These disorders include retinal necrosis, cytomegalovirus infection, sarcoidosis, toxoplasmosis, Eales' disease, Behçet's syndrome, and Vogt-Koyanagi-Harada syndrome [7,14].

- Genetic Disorders: ME can be a complication of retinitis pigmentosa, which is a genetic disorder that affects peripheral and side vision [8].

\section{ME Pathogenesis}

Macular edema can be of two types: intracellular and extracellular. Intracellular accumulation of fluid occurs due to the variation of the cellular ionic distribution as an immediate result of ischemia, toxic cell damage, or trauma. This condition is not very frequent and it is also known as cytotoxic edema. On the other hand, extracellular accumulation of fluid is clinically more relevant and frequent. It is directly associated with the change in the blood-retinal barrier (BRB) [15]. As briefly discussed in the previous section, ME can occur in several different retinal diseases. According to all those diverse underlying pathological events, the morphologic appearance of $\mathrm{ME}$ might diverge according to the underlying disease. In this section, we will systematically discuss the pathogenesis of $\mathrm{ME}$ in various diseases or conditions.

\subsection{Retinal Vascular Diseases}

\section{Diabetic Macular Edema}

The prime cause of blindness across the globe is the diabetic retinopathy (DR), which is a common ocular disease in the case of the patients of diabetes. The ME develops in DR, referred to as diabetic macular edema (DME), is the main cause of vision loss. The severity may range from mild and asymptomatic to permanent loss of vision. DME can be characterized as retinal thickening within two disc diameters of the foveal centre. It can be either focal or diffuse in distribution. Focal edema is often allied with circinate rings of hard exudates, basically the lipoprotein deposits, as a result of leakage from microaneurysms. With further leakage from both microaneurysms and retinal blood vessels, diffuse edema occurs because of the extensive breakdown of the BRB. There might be cystic changes within the macula, indicating focal combination of exudative fluid. Fig. 1 shows the Diabetic Retinopathy images with visible clinical features. DME becomes clinically significant ME (CSME) when any of the following conditions are satisfied $[3,16]$ :

- Any retinal thickening within $500 \mu \mathrm{m}$ radius of the foveal centre.

- Hard exudates within $500 \mu \mathrm{m}$ of the foveal centre and are associated with adjacent retinal thickening $\geq 500 \mu \mathrm{m}$ from the foveal centre. 
- Any part of an area of retinal thickening of size at least 1 disc diameter located within 1 disc area of the foveal centre.

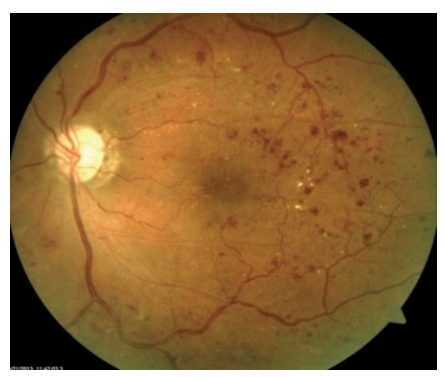

Figure 1. Diabetic Retinopathy

\section{Macular Edema in Retinal vein occlusion}

Retinal vein occlusion (RVO) is the next prime retinal blood vascular disease causing blindness. The obstructions in veins cause $\mathrm{ME}$, which is a major cause of visual loss in patients suffering from central retinal vein occlusion (CRVO) or/and branch retinal vein occlusion (BRVO). The severe or chronic ME ( $>8$ months) disrupts the minuscule intraretinal connections, grounds intracellular damage to the visual elements, and finally causes permanent dwindling of vision [15]. Ischemic ME following BRVO is often transitory and has a better prognosis for visual acuity as compared to perfused ME $[17,18]$. Another significant point is that the development of fluid blood levels in central cystoid spaces can lead to the cystic change in $\mathrm{ME}$ transforming it to CME. Cystic change is more common in RVO than DR. Fig. 2 shows the fundus image of RVO.

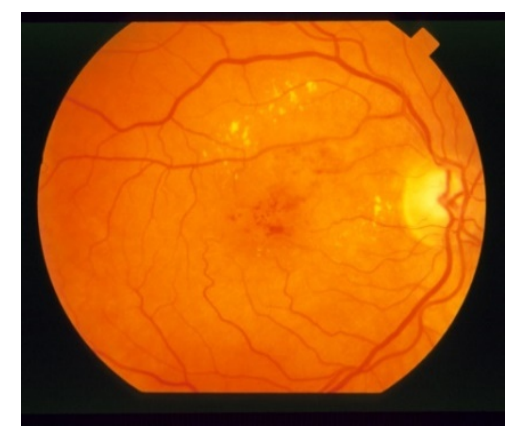

Figure 2. Retinal Vein Occlusion

\section{Age-Related Macular Degeneration}

Age-related Macular Degeneration (AMD) is the leading cause of permanent vision loss among people aged over 60 . In most cases, AMD can be in either dry form or wet form. The dry form of AMD is more common; however, the dry form can lead to the wet form. Only about $10 \%$ of people with macular degeneration get the wet form. In case of dry AMD, yellow deposits, called drusen, appear in the macula. A few small drusen barely cause any changes in the vision. But, when these get bigger and started appearing in large number, they significantly dim or distort vision. As the condition gets worse, the light-sensitive cells in macula get thinner and eventually die, causing permanent loss of central vision. Neovascularization occurs in wet AMD. The new blood vessels growing underneath the macula leak blood and fluids into the retina. The bleeding vessels form scars and permanently damage central vision [11,19]. Fig. 3 shows the retina with AMD.

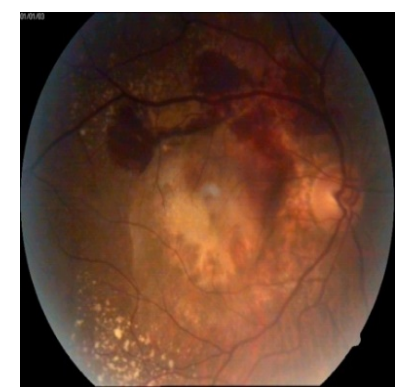

Figure 3. Age-Related Macular Edema

\subsection{ME associated with Post Ophthalmic Surgery}

Cystoid Macular Edema (CME) is a common cause of reversible vision loss following ophthalmic surgery. CME following cataract surgery was initially reported by Irvine in 1953 and is known as the Irvine-Glass syndrome [20]. The underlying pathogenesis of DME is slightly different from that of ME in post-cataract surgery. In pseudophakic cystoid macular edema (PCME), ME is thought to be caused by proinflammatory cytokine release. It is difficult to differentiate between $\mathrm{ME}$ in diabetic patients and $\mathrm{ME}$ after contract surgery or PCME. In some cases, fluorescein angiography may offer better understanding in the underlying cause, as the presence of a disc edema and a "hot disc" can be symptoms for PCME. But then again, this finding can be indecisive, because not all patients with PCME exhibit this clinical feature and moreover, patients with DME may also have disc hyper-fluorescence. The incidence of clinically significant PCME after uncomplicated cataract surgery ranges between $0.1 \%$ and $2.3 \%$, and peaks at approximately 5 weeks in a healthy population. The incidence rate gets significantly higher that is around $16.3 \%$ in patients previously suffering from DME and in patients with DR, whose BRB has been disrupted even before surgery [21]. Generally, clinically significant CME occurs within 3-12 weeks of post-surgery, however, in some cases its onset gets delayed for months or many years after surgery. Earlier, it has been reported that $69 \%$ of the eyes in which clinically significant ME ascended in the first 6 months after cataract surgery showed spontaneous tenacity of macular edema [22]. Albeit, it has been reported that CME persisted in all eyes in which ME had been present during the time of surgery. Additionally, CME is one of the leading causes of diminishing visual acuity after cataract surgery in uveitis patients $[6,21]$. 


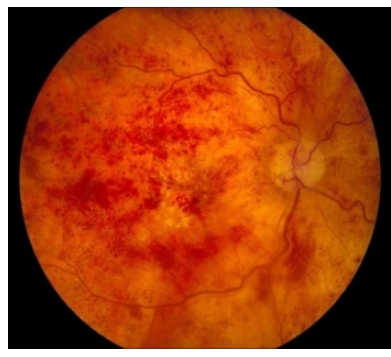

Figure 4. Cystoid Macular Edema after Glaucoma Surgery

Similarly, CME is associated with post Glaucoma surgery as shown in Fig. 4. Two of the popular methods for Glaucoma surgery are Glaucoma Drainage Implants (GDI) and Tube Versus Trabeculectomy (TVT). The target of GDI is to lower the intraocular pressure by the surgical placement of an artificial filtering device. The TVT study reported that there is a higher post-operative CME in the GDI group compared to the trabeculectomy group. In their study, about $22.2 \%$ of patients those who enrolled in their study (41 out of 185 patients) developed visually significant CME following GDI surgery [5].

\subsection{Macular Edema associated with Uveitis:}

Uveitis is an inflammatory disease at the uveal tract that can lead to significant visual impairment. The uveal tract is the vascular layer that lies between the sclera and the neuroretina. According to the location of the inflammation, Uveitis can be classified into anterior, intermediate, posterior and panuveitis. The chronic inflammation breaks down either inner/outer or both BRBs leading to the Uveitic Macular Edema (UME). The UME can be found in the outer nuclear layer or it can be extended more ostensibly or deep before beginning to affect all retinal layers. It can even present in the form of a serious retinal detachment. A UME might complicate an intermediate, anterior, or a posterior uveitis. Intermediate uveitis is the least common type of uveitis; but, with the highest frequency of ME within the range of $25 \%$ to $70 \%$. ME rate in posterior uveitis is 19 $34 \%$ and in panuveitis is $18-66 \%$ [23]. In non-infectious uveitis, ME is the most common complication, as it occurs in $8.3 \%$ of patients, followed by epiretinal membrane $6.3 \%$ and glaucoma 4.2\% [24]. Fig. 5 shows the ME in Uveitis.

The rapidly growing technology for Computer-Aided Detection (CAD) for medical images has significantly improved the accuracy and consistency of the radiologists' image interpretation (Shiraishi et al., 2014). In that context, the early and automatic diagnosis of any retinal abnormality can prevent the patient from total vision loss, facilitate early treatment, and help ophthalmologists to reduce unintentional error in diagnosis and save their time and effort. In the following sections, we are going to discuss various retinal imaging techniques, highlight some of the methods used for retinal abnormality detection, and evaluate the research gap in this field.

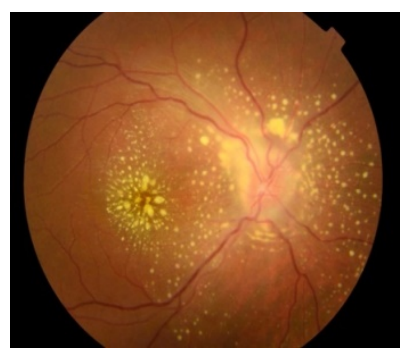

Figure 5. Uveitis

\section{Retinal Imaging Techniques}

From the previous section, we can see that various imperative diseases manifest themselves in the retina and originate either in the eye, the cardiovascular system, or the brain [25]. Evaluation of such diseases involves direct and indirect ophthalmoscopy. The rapid advancement in the retinal imaging techniques has made it the backbone of the clinical care and management of the patients with retinal as well as systemic diseases. There are various imaging modalities for the screening, evaluation, diagnosis, and treatment of diverse appearances and manifestations of the diseases such as diabetic retinopathy, age related macular edema, retinal vein occlusion etc. $[25,26]$. Some of the popular retinal imaging modalities are as follows:

\subsection{Fundus Photography:}

Fundus photography is the most widely used retinal imaging technique for population-based, large scale detection of diabetic retinopathy, retinal vein occlusion, age-related macular degeneration, and glaucoma [25,27]. Traditionally, retinal fundus photography can be performed using film. However, more recently digital fundus photography has become popular as it facilitates easy analysis, magnification, and manipulation of the images [25]. Additionally, fundus photography allows documentation as well as monitoring for improvement or progression of the disease over time.

Fundus imaging is a 2-D representation of the retinal semitransparent tissues projected onto the imaging plane, where the image intensities represent the amount of a reflected quantity of light. There are different categories of fundus imaging techniques.

i) Color fundus: image intensities represent the amount of reflected Red, Green, and Blue wavebands, as determined by the spectral sensitivity of the sensor.

ii) Red free fundus: image intensities represent the amount of reflected light of a specific waveband.

iii) Stereo fundus: image intensities represent the amount of reflected light from two or more different view angles for depth resolution.

iv) Hyperspectral imaging: image intensities represent the amount of reflected light of multiple specific wavelength bands. 
v) Scanning laser ophthalmoscopy (SLO): image intensities represent the amount of reflected single wavelength laser light obtained in a time sequence.

vi) Adaptive optics SLO: image intensities represent the amount of reflected laser light optically corrected by modelling the aberrations in its wave-front.

Apart from the image intensity representation, fundus imaging can be further categorized in terms of angle of capturing image. Those are $[25,26,28]$ :

i) Standard fundus image: Standard fundus photography captures $30^{\circ}$ of the posterior pole of the eye, which includes the macula and the optic nerve as shown in Fig. 1-5. The main advantages of this type of color fundus include ease of use, highly accessible, and useful for effective documentation. This form is useful for diagnosing macular edema as certain morphologic features, such as hard exudates, are easily identifiable on color photographs. However, it cannot confirm clinically significant macular edema (CSME) as fine details are often ostensible, and any media opacity can be obstruction in obtaining good quality image.

ii) Wide-field fundus image: The wide-field fundus photography can image posterior as well as the peripheral retina. In this type of fundus image, seven fundus fields are collected and combined to create a montage image that shows a $75^{\circ}$ field of view as shown in Fig. 6. The new advanced fundus cameras can capture up to a $200^{\circ}$ field of view, which covers $80 \%$ of the total surface retinal area even with an undilated pupil. Therefore, it helps in analysing the peripheral retinal pathology, detects any abnormality in a minimally invasive fashion, and facilitates more thorough documentation. However, the equipment cost for capturing wide filed images is quite high. Another limitation is that the images often get distorted due to eyelash artifacts, the spherical nature of the globe, and false color representation of fundus findings. Because of these limitations, traditional $30^{\circ}$ fundus photography continues to be the standard method to photograph the fundus $[25,26,28]$.

iii) Stereoscopic fundus image: A stereoscopic image can be produced by capturing photographs of the retina from two slightly different positions as shown in Fig. 7. Many fundus cameras are capable of capturing stereoscopic image of the central and peripheral retina by sequentially taking two images. This form of imaging technique provides a three-dimensional view of the retina with a depth perception while examining the patient's pathology. Therefore, it helps to distinguish subtle extra-retinal neovascularization elevated above the plane of the retina from intra-retinal microvascular abnormalities. However, in clinical practice, it is time consuming and difficult for the physician to interpret pathology from the stereoscopic photos $[25,28,29]$.

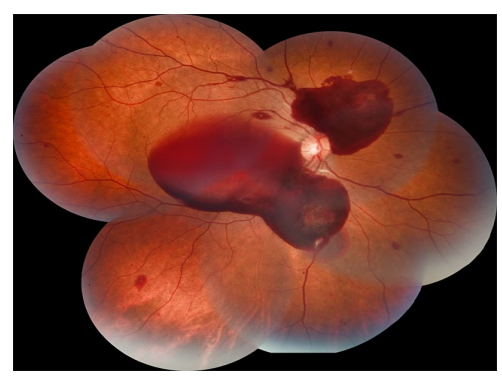

Figure 6. Wide-field Fundus Image

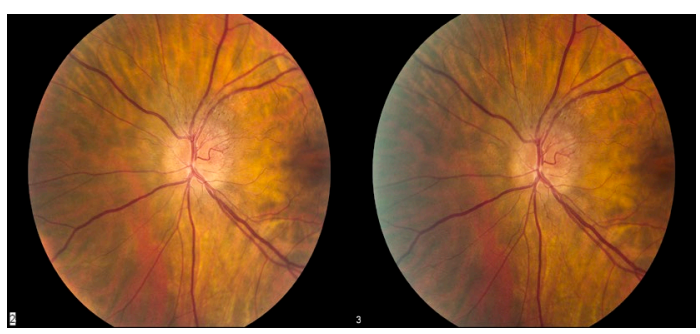

Figure 7. Stereoscopic fundus image

\subsection{Fluorescein Angiography}

In 1967, this widely popular imaging technology was first introduced into mainstream ophthalmology by Gass. Before capturing Fluorescein Angiography (FA) image sodium fluorescein, a fluorescent mineral-based dye, is injected into the subject's bloodstream. When Sodium fluorescein molecules running through arteries and veins in the eye are excited by blue excitation filter of the camera, it then emits yellow-green light. Thus, the image intensities represent the amounts of emitted photons from the fluorescein. Fig. 8 shows an angiographic fundus image. FA is useful in evaluating the retinal vasculature and hence, as it is presently the gold standard for diagnosing diabetic eye disease [25,30]. FA is good for diagnosis of choroidal disorders and neovascular macular degeneration. FA image can identify microaneurysms those manifest as punctate areas of hyperfluorescence. Retinal neovascularization also can cause fluorescein leakage, and FA is a useful test to confirm the diagnosis of neovascularization of the disc and elsewhere in proliferative diabetic retinopathy Apart from standard FA image, there is wide field FA imaging technique. The wide field FA is useful in detecting the peripheral neovascularization, as well as the extent of retinal nonperfusion that are difficult to visualize with standard field FA. Fig. 8 shows the wide field FA image example.

There are certain limitations of FA imaging technique. It is not part of the ETDRS criteria to determine CSME in patients. FA is not effective for determining treatment parameters and success of therapy for macular edema. Most importantly, the fluorescein dye has lots of side effects. It can cause transient nausea in case of about $2.9 \%$ patients and vomiting in $1.2 \%$ of patients and various allergic reactions. 


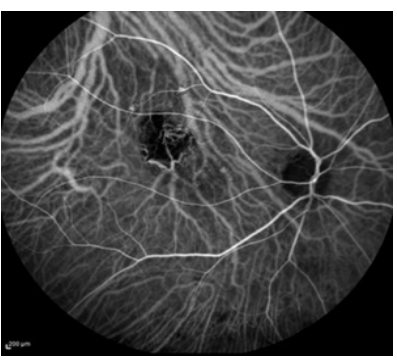

a)

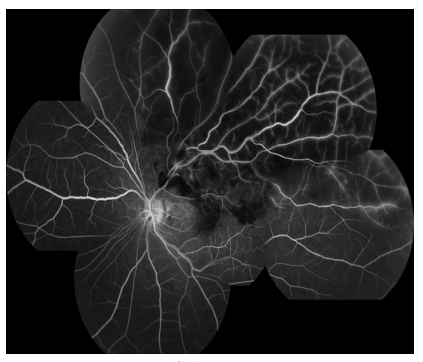

b)

Figure 8. a) Standard FA image, b) Wide-field FA image

\subsection{OCT Image}

Optical coherence tomography imaging technique has been commercially available since 1996. OCT image provides microscopic resolution. The working principle of OCT imaging technique is similar to the ultrasonography process. OCT uses light waves to capture the picture of crosssectional area of the retina. It employs white light, also known as low-coherent light, interferometry. The white light illumination causes backscatter from the retina and helps in estimating the depth. The low coherent OCT light, which has the longer wavelength than visible light, scans across the macula rapidly and captures multiple OCT A-scans images, then all images are combined to form a linear image. It penetrates deeper into retinal and choroidal tissue, and thus, the ophthalmologist can observe each of the distinct layers of the retina using OCT image. The analysis software uses computer algorithms to measure retinal thickness by automatically outlining the inner and outer retinal boundaries. These measurements help to diagnose and also provide treatment guidance for various retinal diseases including glaucoma, age-related macular degeneration, and diabetic retinopathy. OCT can also reveal loss of different layers of the retina, such as the photoreceptors or nerve fibre layer, which can sometimes help to explain visual loss in patients without other macular abnormalities. The older OCT devices used to acquire maps by combining data from six linear images. Newer spectral domain OCT devices create macular maps using a much larger amount of OCT data[25,29,31]. Fig. 9 shows the OCT image.

In an OCT device, there is a beam splitter to split the light into the two beams: one beam reflects on the retinal tissue, called sample arm, and the other beam reflects from the reference mirror, called the reference arm. With the help of photo sensors, the interferogram energy between these two reflective beams is converted into image intensities. From these intensities, a depth scan with different intensities, also known as an A-scan, is created that represents the backscatter at different depths. Different factors such as patients' comfort, reduce motion artifacts, obtain high image resolution etc. mainly depend on attaining short A-scan imaging intervals. Therefore, various methods have been used to maximize the rate of capturing A-scans per unit of

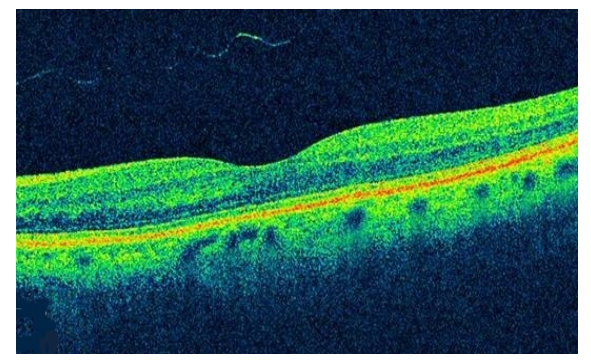

Figure 9. OCT image

-time. There are three main OCT principles developed to generate an A-scan image for measuring the desired retinal tissue depth [25,29,32].

i) Time-domain OCT: Thousands of A-scans can be acquired per second by moving the reference mirror mechanically to different positions.

ii) Swept-source OCT: The light source is rapidly adjusted over its centre wavelength and the correlogram for each such wavelength is measured over time using a photo sensor.

iii) Spectral-domain OCT: A broadband light source is used and the interferogram is spectrally disintegrated using diffraction grating and photo sensors.

To overcome the limitation of time taken by an A-Scan OCT, B-Scans are developed where the correlogram intensities are presented in the form of 2-D slices. In the Bscan, a single sweep of the beam scans over the retina in a linear or circular fashion. Depending on the quantity of Ascans that can be acquired over time, the retina can be imaged either two-dimensionally or three-dimensionally. 3$\mathrm{D}$ imaging is possible with spectral-domain OCT as it can acquire tens of thousands of A-scans per second. However, the commercially available time-domain OCT is not suitable for 3-D imaging as it captures upto 400 A-scans per second. Thus, it can be observed that obtaining a 2-D or 3-D OCT image is largely depends on the scanning speed versus the amount of time available for scanning. Currently, some commercially available scanners are capable of acquiring close-to-isotropic 3-D volumes [25,31].

\section{State-of-the-Art for Retinal Abnormality Detection}

The literature survey provides plenty of work for automatic detection of ocular disease such as Diabetic Retinopathy (DR), Glaucoma, Age-related Macular Degeneration (AMD) etc. However, only a few research works focused on detecting the threat to the central vision regardless of the type of ocular diseases. Majority of research works revolve around detection of Diabetic Retinopathy as it is the prime reason of the vision loss across the world. 


\subsection{Methods for Diabetic Retinopathy (DR) detection}

In the past twelve years, several research works have been carried out to develop automated DR diagnosis methods using different clinical features such as microaneurysms, haemorrhages, exudates, blood vessels, node points, and textures etc. Those methodologies are mainly dependent on the segmentation of bright lesions and red lesions, comprising several steps.

The bright lesions found in DR are mainly Hard-Exudates and Cotton Wool Spots. These bright lesions are lipoprotein deposited in the retina due to vascular leakage [33]. The red lesions occur in the DR are mainly Microaneurysms (MA) and Haemorrhages. MAs are tiny lumps in the walls of retinal blood vessels [34]. Sinthanayothin et al., 2003, used region growing where starting from a seed points the neighbouring pixels are analyzed to detect bright lesions. Fleming et al. and Jelinek et al. used region growing method for MA detection [34,35]. A very popular method, thresholding method based on the foreground and background pixels difference has been used in [36-38]. Various researchers used a morphological operator to detect bright lesions [39,40] and red lesions [41]. A wavelet-based method is proposed in [42] for red lesions detection. Machine learning classifiers such as Neural Network, Support Vector Machine, and radial basis function are used to segment bright lesions in [43]. Zhang et al. 2010 and Lazar \& Hajdu 2013 used a hybrid approach to detect MA $[44,45]$.

Majority of the DR screening methods are evaluated for 2-class classification, i.e. DR or No DR [46,47]. Usman Akram et al., developed an NPDR grading method in where NPDR is graded into mild, moderate and severe based on the type and numbers of red lesions and exudates [48]. Dupas et al., 2010, determined the severity of DR based on the presence of red lesions. According to the type of red lesions and their corresponding numbers, the retina images are graded into $0,1,2$, and 3 . Moreover, the risk of macular edema (ME) is evaluated by measuring the distance of exudates and fovea [49]. Mookiah et al., 2013, exploited Genetic Algorithm optimized Probabilistic Neural Network (PNN) to classify NPDR, PDR and Normal image using features like bifurcation points and area of the blood vessels, exudates, texture, and entropies. In four-class Classification viz. normal, moderate NPDR, severe NPDR and PDR. Acharya et al., presented an automatic DR detection system using a combination of texture and obtained an accuracy of $85.2 \%$ [50]. In [51,52] a CAD was developed, which achieved sensitivity above $90 \%$ for detecting referable retinopathy. Many of these automatic Computer Aided Diagnostic (CAD) methods are commercially available as retinal image analysis systems [53]. Some of the commercially available systems are Retinalyze System $\AA$, iGradingM $\AA$, IDx-DR $\AA$, RetmarkerDR $\AA$, etc. These CAD systems effectively applicable for DR screening and identify the retina affected by DR or referable DR. However, all these methods are unable to identify the high-risk DR or the presence of Diabetic Macular Edema (DME) [53].
The recent advancement in deep learning has unlocked the path of a new methodology for retinal image analysis. Gulshan et al., 2016, used Inception V3 architecture for detecting moderate and worse diabetic retinopathy, which is considered as referable diabetic retinopathy, then, referable diabetic macular edema, or both [54]. Doshi et al., used deep convolutional neural networks for automated diagnosis and classification of five stages of the Diabetic Retinopathy based on severity. They designed a CNN architecture comprising of five sets of combination of convolution, pooling and dropout layers in sequence [55]. Chandore et al., 2017, used a deep CNN model of 15 layers to classify DR and non-DR images [56]. Table-1 summarizes the stateof-the-art methods for DR detections.

\subsection{Methods for DME Detection}

Macular Edema associated with DR is known as Diabetic Macular Edema (DME). As discussed in Section 2.1., the clusters of exudates situated in the macular region can be an indication to macular edema, which is the main cause of visual loss in DR patients. The research work focusing on DME detection is relatively lower than that of DR even after the fact that ME is the cause of vision loss in DR. As we can see from the review on DR detection, most of the methods are focused on segmentation of red and bright lesions and their counts for DR detection, those methods are not useful for detecting DME. A few research works are available on DR severity detection and because of the fact that ME condition arises starting from moderate/severe NPDR to PDR they didn't particularly mention the ME condition. Majority of the DME detection methods depends on segmentation of hard exudates and their positions near the macula region. Dupas et al., evaluated the risk of ME by measuring the distance of exudates from fovea [49]. A popular DR screening system is IDx-DR ${ }^{\circledR}$ [57-59]. This system was validated for referable DR detection including DME on a database of 1748 fovea-centred images. Srinivasan et al., 2014., proposed an automated DME and AMD detection method for OCT images using multiscale histograms of oriented gradient descriptors and support vector machine [60]. Sengar et al., used a region growing method to detect DME region from DR images. DME severity was accessed using scaling of bright lesions in the macular region [61]. Gulshan et al., 2016 used deep learning model to detect referable DR and in their method, they also evaluated the presence of DME. Kumar and Ravichandran, 2017 proposed DME severity detection based on Extreme Learning Machine (ELM) classifier. Using ELM, they detected hard exudates in colour fundus images and classified the images according to severity level based on the appearance of hard exudates near the macula region [54]. Wang et al., 2016, proposed an improved level set algorithm for segmentation using linear configuration pattern (LCP) based features and detection of DME in the OCT image [62]. Singh and Gorantla, 2020, proposed a DMENet, which is a hierarchical ensemble CNN for detection of DME [63]. Table-2 shows some of the DME detection methods. 
Table 1. State-of-the-art for DR Detection

\begin{tabular}{|c|c|c|c|c|c|}
\hline Author & Features & Methods & Target Class & Database & Performance \\
\hline $\begin{array}{l}\text { Neimeijer et al. } \\
(2007)\end{array}$ & $\begin{array}{l}\text { Bright } \\
\text { lesions }\end{array}$ & $\mathrm{k}-\mathrm{NN}$ & DR, Normal & In house data & $\begin{array}{l}\text { Sensitivity }=95 \% \\
\text { Specificity }=86 \%\end{array}$ \\
\hline $\begin{array}{l}\text { Quellec et al. } \\
(2008)\end{array}$ & $\begin{array}{l}\text { Red } \\
\text { lesions }\end{array}$ & Wavelet based & DR, Normal & $\begin{array}{l}\text { Hospital } \\
\text { database }\end{array}$ & $\begin{array}{l}\text { Sensitivity }=89.6 \% \\
\text { Specificity }=89.5 \%\end{array}$ \\
\hline $\begin{array}{l}\text { Sanchez et al. } \\
(2008)\end{array}$ & $\begin{array}{l}\text { Bright } \\
\text { lesions }\end{array}$ & $\begin{array}{l}\text { Thresholding, } \\
\text { Fisher }\end{array}$ & DR, Normal & In house data & $\begin{array}{l}\text { Sensitivity }=100 \% \\
\text { Specificity }=100 \%\end{array}$ \\
\hline $\begin{array}{l}\text { Nayak et al. } \\
(2008)\end{array}$ & $\begin{array}{l}\text { Exudates, } \\
\text { vessel, and } \\
\text { contrast }\end{array}$ & Neural Network & $\begin{array}{l}\text { Normal, } \\
\text { NPDR, PDR }\end{array}$ & $\begin{array}{l}\text { Hospital } \\
\text { database }\end{array}$ & $\begin{array}{l}\text { Sensitivity }=90 \% \\
\text { Specificity }=100 \% \\
\text { Accuracy }=93 \%\end{array}$ \\
\hline $\begin{array}{l}\text { Gracia et al. } \\
(2009)\end{array}$ & $\begin{array}{l}\text { Bright } \\
\text { lesions }\end{array}$ & $\begin{array}{l}\text { MLP, RBF, } \\
\text { SVM }\end{array}$ & DR, Normal & In house data & $\begin{array}{l}\text { Sensitivity }=100 \% \\
\text { Specificity }=92.6 \%\end{array}$ \\
\hline $\begin{array}{l}\text { Jaafar et al. } \\
(2010)\end{array}$ & $\begin{array}{l}\text { Bright } \\
\text { lesions }\end{array}$ & Thresholding & DR, Normal & DIARETDB & $\begin{array}{l}\text { Sensitivity }=91.2 \% \\
\text { Specificity }=99.3 \%\end{array}$ \\
\hline $\begin{array}{l}\text { Jaafar et al. } \\
\text { (2011) }\end{array}$ & $\begin{array}{l}\text { Red } \\
\text { lesions }\end{array}$ & $\begin{array}{l}\text { Morphology } \\
\text { based }\end{array}$ & DR, Normal & DIARETDB & $\begin{array}{l}\text { Sensitivity }=98.8 \% \\
\text { Specificity }=96.2 \%\end{array}$ \\
\hline $\begin{array}{l}\text { Inoue et al. } \\
(2013)\end{array}$ & $\begin{array}{l}\text { Red } \\
\text { lesions }\end{array}$ & $\begin{array}{l}\text { Morphology } \\
\text { based, PCA, } \\
\text { ANN }\end{array}$ & DR, Normal & $\begin{array}{l}\text { ROC } \\
\text { database }\end{array}$ & Sensitivity $=72.9 \%$ \\
\hline $\begin{array}{l}\text { Acharya et al. } \\
(2012)\end{array}$ & $\begin{array}{l}\text { Co- } \\
\text { occurrence } \\
\text { matrix } \\
\text { and run } \\
\text { length } \\
\text { matrix }\end{array}$ & SVM & $\begin{array}{l}\text { normal, } \\
\text { moderate, } \\
\text { severe } \\
\text { NPDR, PDR }\end{array}$ & $\begin{array}{l}\text { Hospital } \\
\text { Database }\end{array}$ & $\begin{array}{l}\text { Sensitivity }=98.9 \% \\
\text { Specificity }=89.5 \% \\
\text { Accuracy }=100 \%\end{array}$ \\
\hline $\begin{array}{l}\text { Zhang et al. } \\
(2014)\end{array}$ & $\begin{array}{l}\text { Bright } \\
\text { lesions }\end{array}$ & Morphology & DR, Normal & $\begin{array}{l}\text { e-ophtha EX } \\
\text { database, }\end{array}$ & $\begin{array}{l}\text { Sensitivity }=96 \% \\
\text { Specificity }=89 \%\end{array}$ \\
\hline $\begin{array}{l}\text { Roychowdhury } \\
\text { et al. (2014) }\end{array}$ & $\begin{array}{l}\text { Red } \\
\text { lesions }\end{array}$ & $\begin{array}{l}\text { Gaussian Mixer } \\
\text { Model, k-NN, } \\
\text { SVM }\end{array}$ & Normal, DR & MESSIDOR & $\begin{array}{l}\text { Sensitivity }=100 \% \\
\text { Specificity }=53.16\end{array}$ \\
\hline $\begin{array}{l}\text { Antal et al. } \\
\text { (2014) }\end{array}$ & $\begin{array}{l}\text { Red } \\
\text { lesions }\end{array}$ & $\begin{array}{l}\text { Ensemble } \\
\text { classifier }\end{array}$ & $\begin{array}{l}\text { Normal, Mild } \\
\text { NPDR, DR }\end{array}$ & MESSIDOR & $\begin{array}{l}\text { Sensitivity }=90 \% \\
\text { Specificity= } 91 \%\end{array}$ \\
\hline $\begin{array}{l}\text { Gargeya et al. } \\
(2017)\end{array}$ & $\begin{array}{l}\text { Image } \\
\text { Pixels }\end{array}$ & $\begin{array}{l}\text { Convolutional } \\
\text { Neural Network }\end{array}$ & DR, Normal & $\begin{array}{l}\text { MESSIDOR 2, } \\
\text { E-Ophtha }\end{array}$ & $\begin{array}{l}\text { AUC=97\% } \\
\text { Sensitivity=94\% } \\
\text { Specificity }=98 \%\end{array}$ \\
\hline $\begin{array}{l}\text { Lam et al. } \\
(2018)\end{array}$ & $\begin{array}{l}\text { Image } \\
\text { Pixels }\end{array}$ & $\begin{array}{l}\text { Convolutional } \\
\text { Neural Network }\end{array}$ & DR, Normal & $\begin{array}{l}\text { Kaggle, } \\
\text { MESSIDOR }\end{array}$ & Sensitivity= 95\% \\
\hline $\begin{array}{l}\text { Zago et al. } \\
(2020)\end{array}$ & $\begin{array}{l}\text { Red } \\
\text { lesions }\end{array}$ & $\begin{array}{l}\text { Convolutional } \\
\text { Neural Network }\end{array}$ & DR, Normal & $\begin{array}{l}\text { DIARETDB } \\
\text { MESSIDOR }\end{array}$ & Sensitivity $=95 \%$ \\
\hline
\end{tabular}

\subsection{Methods for RVO Detection}

The automatic detection of RVO is relatively novel in the field of CAD as compared to DR, AMD, etc. The literature review on automatic detection of RVO is inadequate. Only a few research works are available to automatically diagnose and detect RVO types. H. Zhang et al. 2014 used Hierarchical Local Binary Pattern (HLBP) to represent the abnormal features of blood vessels to detect $\mathrm{BRVO}$ in fluorescein angiography (FA) images. Inspired by the convolutional neural network, hierarchical combination of
Liner Binary Pattern (LBP) and max pooling is proposed [64]. Anitha et al., 2009 developed an automatic eye disease detection system where CRVO is one of the considered eye diseases along with the other three. Fuzzy C-means clustering is applied for feature extraction from the images and Back Propagation Neural Network (BPNN) or minimum distance classifier is used for classification [65]. Fazekas et al., 2015 applied fractal analysis on two blood vessel segmentation methods to learn the normal and abnormalblood vessels [66]. Similarly, in [67] fractal analysis is used 
Table 2. State-of-the-Art of DME Detection

\begin{tabular}{|c|c|c|c|c|c|}
\hline Author & Features & Methods & Target Class & Database & Performance \\
\hline $\begin{array}{l}\text { Dupas et al. } \\
(2010)\end{array}$ & $\begin{array}{l}\text { Red } \\
\text { lesions, } \\
\text { Exudates }\end{array}$ & k-NN & $\begin{array}{l}\text { DME, DR, } \\
\text { Normal }\end{array}$ & MESSIDOR & $\begin{array}{l}\text { Sensitivity }=83.9 \% \\
\text { Specificity }=72.7 \%\end{array}$ \\
\hline $\begin{array}{l}\text { Srinivasan et } \\
\text { al. } \\
(2014)\end{array}$ & $\begin{array}{l}\text { Retinal } \\
\text { Layers }\end{array}$ & SVM & $\begin{array}{l}\text { DME, AMD, } \\
\text { Normal }\end{array}$ & $\begin{array}{l}\text { SD-OCT data } \\
\text { sets of Duke } \\
\text { University }\end{array}$ & Accuracy $=100 \%$ \\
\hline $\begin{array}{l}\text { Sengar et al. } \\
\text { (2015) }\end{array}$ & $\begin{array}{l}\text { Bright } \\
\text { lesions }\end{array}$ & $\begin{array}{l}\text { Region based } \\
\text { method }\end{array}$ & DME, Normal & MESSIDOR & Accuracy $=90 \%$ \\
\hline $\begin{array}{l}\text { Gulshan et al. } \\
\text { (2016) }\end{array}$ & $\begin{array}{l}\text { Image } \\
\text { pixels }\end{array}$ & Deep learning & $\begin{array}{l}\text { DR, DME, } \\
\text { Normal }\end{array}$ & $\begin{array}{l}\text { EyePACS-1, } \\
\text { MESSIDOR }\end{array}$ & $\begin{array}{l}\text { Sensitivity }=97.5 \% \\
\text { Specificity }=93.4 \%\end{array}$ \\
\hline $\begin{array}{l}\text { Kumar et al. } \\
\text { (2017) }\end{array}$ & Exudates & ELM classifier & DME, Normal & Drive & $\begin{array}{l}\text { Accuracy }=98 \% \\
\text { Sensitivity }=99 \% \\
\text { Specificity }=98 \%\end{array}$ \\
\hline $\begin{array}{l}\text { Wang et al. } \\
(2016)\end{array}$ & $\begin{array}{l}\text { Retinal } \\
\text { Layers }\end{array}$ & LCP & $\begin{array}{l}\text { DME, AMD, } \\
\text { Normal }\end{array}$ & $\begin{array}{l}\text { SD-OCT data } \\
\text { sets of Duke } \\
\text { University }\end{array}$ & Accuracy $=100 \%$ \\
\hline $\begin{array}{l}\text { Singh et al. } \\
(2020)\end{array}$ & $\begin{array}{l}\text { Image } \\
\text { pixels }\end{array}$ & Deep learning & DME, Normal & $\begin{array}{l}\text { MESSIDOR, } \\
\text { IDRiD }\end{array}$ & $\begin{array}{l}\text { Accuracy }=96.1 \% \\
\text { Sensitivity }=96.3 \% \\
\text { Specificity }=95.8 \%\end{array}$ \\
\hline
\end{tabular}

-for detecting BRVO. They used Box Counting Method, Mass-Radius method and Density-Density Correlation method to calculate the fractal dimension. Out of these three methods, Box counting and Mass-Radius method gives more accurate results. Gayathri et al. 2014, used blood vessel as features to diagnose the possible blockage in the vein. At first, the blood vasculature is segmented [68]. Then, Completed Local Binary Pattern (CLBP) is performed to extract the textures of the blood vessel. With the regression plots, they showed the feasibility of their method to detect retinal blood vascular disease like RVO.

The deep learning approach is first exploited in [69] for BRVO detection. They used a classical $\mathrm{CNN}$ model to classify the normal and BRVO colour fundus images via image-based and patch-based approaches. Another CNN model is proposed by [70] to detect CRVO using colour fundus image using image-based method. Table-3 summarizes the state-of-the-art method for RVO detection

\subsection{Methods for AMD Detection}

There are plenty of automated methods for AMD detection as it is the third popular reason for vision loss after DR and RVO. Agurto et al. used various pathologic conditions, including microaneurysms, haemorrhages, exudates, neovascularization in the optic disc and elsewhere, drusen, abnormal pigmentation, and geographic atrophy to classify DR and AMD affected abnormal image from the normal image [71]. In [19] biologically inspired features are used from the macula region and used Support Vector Machine to detect AMD. Garnier et al. used multiresolution texture analysis to detect AMD in colour fundus images. The relevant texture patterns are extracted from the Local Binary Pattern and used a Linear Discriminant Analysis to classify the images [72]. Srinivasan et al. proposed an automated DME and AMD detection method for OCT images using multiscale histograms of oriented gradient descriptors and support vector machine [60]. In [73,74] deep Convolutional Neural Network is used to detect AMD using colour fundus image. Table 4 shows some of the state-of-the-art methods for AMD detection.

Discussion: From the vast literature review on retinal abnormality detection, it can be observed that the majority of the computer-aided methods are disease-specific. The main cause of blindness in any of these diseases is macular edema. Early detection of these diseases is always desired in order to prevent complete blindness. However, early detections of retinal abnormalities causing vision loss are still a challenge. Therefore, the methods that focused on detecting associated macular edema at the earliest stage are seemed to be more beneficial in terms of preventive measure. Most of the automated diagnostic methods are for DME detection. Handfuls of methods are available for AMD detection. There is no method for diagnosing macular edema associated with RVO. One important point to be noted is that often macular edema and cystoid macular edema are considered to be same, but, it is not. ME is called CME when there is any cystic change and it is mainly associated with post-ophthalmic surgery, including cataract and glaucoma surgery [6]. There is no automated method available for the detection of CME. Recently, researchers are focusing on diagnosing CME using OCT images. Again, there is a lack of automated diagnostic method that can diagnose multiple retinal abnormalities simultaneously and 
give alert for a possible threat to vision. Since, the main cause of the blindness in any retinal abnormalities, such as $\mathrm{DR}$, RVO, AMD, Uveitis, post-ophthalmic surgery, is macular edema condition; therefore, we justify the idea that it is better to focus on macula region to prevent any cause of blindness. In this paper, we propose a simple automated method to analyze the macula region and detect any abnormality, which can be a threat to central vision irrespective of the disease type.

Table 3. State-of-the-Art of RVO Detection

\begin{tabular}{|c|c|c|c|}
\hline Author & Target Class & Method & Remarks \\
\hline Zhang et al. (2014 ) & BRVO & $\begin{array}{l}\text { Hierarchical Local } \\
\text { Binary Pattern, Support } \\
\text { Vector Machine }\end{array}$ & Accuracy $96.1 \%$. \\
\hline Zhao et al. (2015 ) & BRVO & $\begin{array}{l}\text { Convolutional Neural } \\
\text { Network }\end{array}$ & $\begin{array}{l}\text { Accuracy } 97 \% \text { (images } \\
\text { based), } 98.5 \% \text { (patch- } \\
\text { based) }\end{array}$ \\
\hline Fazekas et. al (2015) & $\begin{array}{l}\text { CRVO, } \\
\text { BRVO, } \\
\text { HRVO }\end{array}$ & $\begin{array}{l}\text { Fractal properties of } \\
\text { blood vessels }\end{array}$ & No performance evaluation \\
\hline Zode et al (2017) & BRVO & Fractal analysis & No performance evaluation \\
\hline J. Anitha et. al (2009) & CRVO & $\begin{array}{l}\text { Fuzzy C-means } \\
\text { clustering, Back } \\
\text { Propagational Neural } \\
\text { Network (BPN) }\end{array}$ & $\begin{array}{l}\text { CRVO is one of the } 4 \text { other } \\
\text { eye diseases for multiclass } \\
\text { classification }\end{array}$ \\
\hline Gayathri et al.(2014) & - & $\begin{array}{l}\text { Complete Local Binary } \\
\text { Pattern, Neural Network }\end{array}$ & $\begin{array}{l}R=0.98 \text { under Regression } \\
\text { plot, } R=0.69 \text { for testing. }\end{array}$ \\
\hline Choudhury et al. (2018) & CRVO & $\begin{array}{l}\text { Convolutional Neural } \\
\text { Network }\end{array}$ & Accuracy $97.6 \%$. \\
\hline
\end{tabular}

Table 4. State-of-the-Art of AMD Detection

\begin{tabular}{|c|c|c|c|c|c|}
\hline Author & Features & Methods & Target Class & Database & Performance \\
\hline $\begin{array}{l}\text { Agurto et al. } \\
(2011)\end{array}$ & $\begin{array}{l}\text { Red lesions, } \\
\text { Exudates, } \\
\text { neovasculari } \\
\text { zation }\end{array}$ & $\mathrm{k}-\mathrm{NN}$ & $\begin{array}{l}\text { AMD, DR, } \\
\text { Normal }\end{array}$ & $\begin{array}{l}\text { Retina Institute } \\
\text { of South Texas, } \\
\text { University of } \\
\text { Texas Health } \\
\text { Science Center }\end{array}$ & $\begin{array}{l}\text { Sensitivity }=94 \% \\
\text { Specificity }=50 \%\end{array}$ \\
\hline $\begin{array}{l}\text { Cheng et al. } \\
(2012)\end{array}$ & $\begin{array}{l}\text { biologically } \\
\text { inspired } \\
\text { features }\end{array}$ & SVM & AMD, Normal & $\begin{array}{l}\text { In house } \\
\text { database }\end{array}$ & $\begin{array}{l}\text { Sensitivity }=86.3 \% \\
\text { Specificity }=91.9 \%\end{array}$ \\
\hline $\begin{array}{l}\text { Garnier et al. } \\
(2014)\end{array}$ & $\begin{array}{l}\text { Local Binary } \\
\text { Pattern }\end{array}$ & $\begin{array}{l}\text { Linear } \\
\text { Discriminant } \\
\text { Analysis }\end{array}$ & AMD, Normal & $\begin{array}{l}\text { In house } \\
\text { database }\end{array}$ & $\begin{array}{l}\text { Accuracy }=93.3 \% \\
\text { Sensitivity }=91.3 \% \\
\text { Specificity }=95.5 \%\end{array}$ \\
\hline $\begin{array}{l}\text { Srinivasan et } \\
\text { al. } \\
(2014)\end{array}$ & $\begin{array}{l}\text { Retinal } \\
\text { Layers }\end{array}$ & SVM & $\begin{array}{l}\text { DME, AMD, } \\
\text { Normal }\end{array}$ & $\begin{array}{l}\text { SD-OCT data } \\
\text { sets of Duke } \\
\text { University }\end{array}$ & Accuracy $=100 \%$ \\
\hline $\begin{array}{l}\text { Burlina et al. } \\
(2016)\end{array}$ & Image pixels & CNN & AMD, Normal & $\begin{array}{l}\text { NIH AREDS } \\
\text { dataset }\end{array}$ & Accuracy $=95 \%$ \\
\hline $\begin{array}{l}\text { Tan et al. } \\
\text { (2018) }\end{array}$ & Image pixels & CNN & AMD, Normal & $\begin{array}{l}\text { In house } \\
\text { database }\end{array}$ & Accuracy $=95.45 \%$ \\
\hline
\end{tabular}




\section{Proposed Method for Retinal Abnormality Detection}

The proposed method is in the early stage of research and we have conducted the initial experiments for the proposed idea. In the proposed method, we have segmented the macula region as our Region of Interest (ROI). After that, we applied Linear Binary Pattern (LBP) and extracted LBP features to k-Nearest Neighbour $(\mathrm{kNN})$ classifier. In the following subsections, we have described the proposed method step by step in details. Fig. 6 shows the block diagram of the overall system and Fig. 7 shows the flow diagram of the proposed method

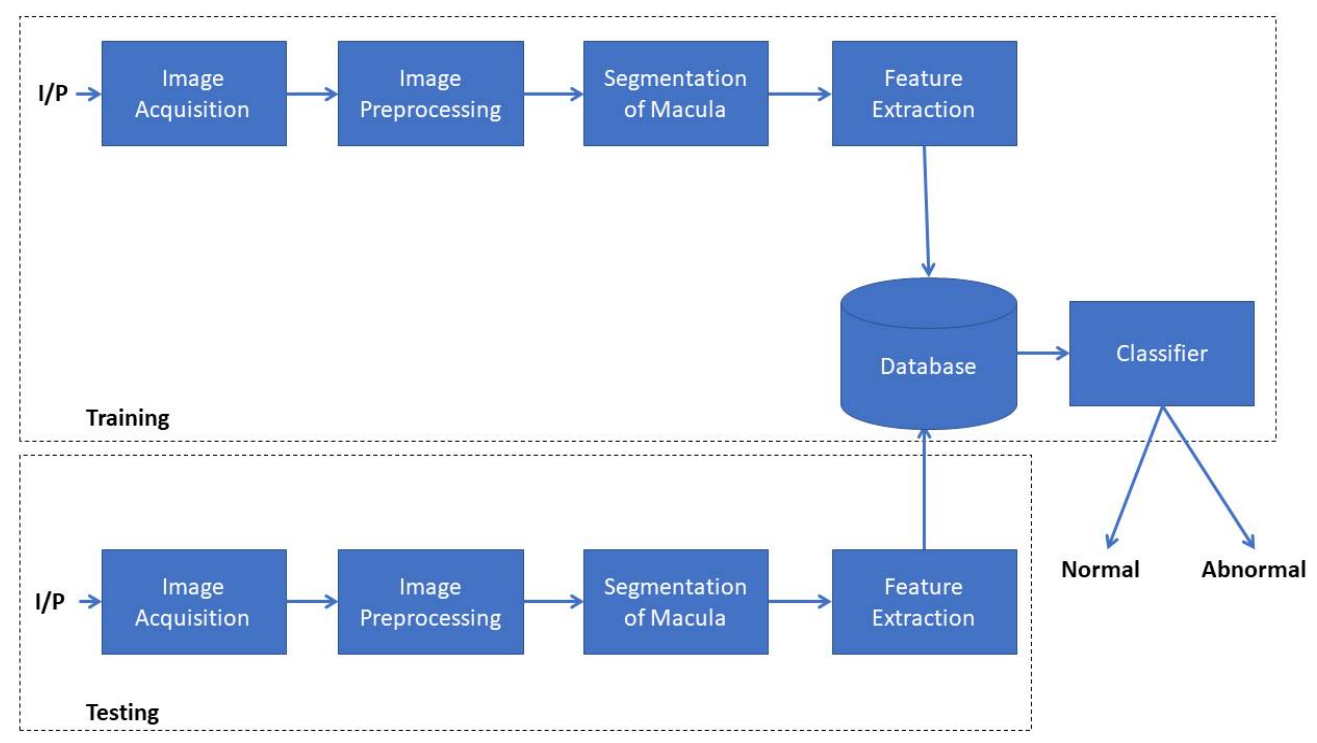

Figure 6. Block diagram of the Overall System for Retinal Abnormality detection

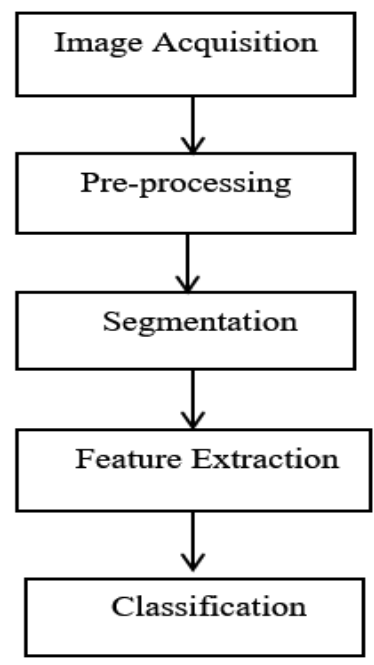

Figure 7. Flow Diagram of the Proposed Method 


\subsection{Image Pre-processing and Segmentation}

Pre-processing is an important step for any classification task. A good pre-processing method enhances the performance of the subsequent steps in a classification problem. In the proposed method, we followed the preprocessing steps used in [75]. After extracting the green channel from the colour fundus image, using Contrastlimited Adaptive Histogram Equalization (CLAHE), the quality of the images is enhanced. However, no image resizing has been done in our case during the preprocessing step. Fig. 8 shows the sample images after performing pre-processing.

Now, the accuracy of image analysis depends on the performance of the segmentation of the image. To prevent blindness due to any retinal abnormality, our main focus is on the macula region. The fovea is the centre of macula and any lesions near macula region can be a possible threat to the central vision. Therefore, our Region of Interest (ROI), which is the macula region, is segmented or isolated using a graphical User Interface (GUI) based bounding box. After selecting the macula region, the segmented image is resized to $100 \times 100$. Fig. 9 shows the steps involved in the segmentation process.

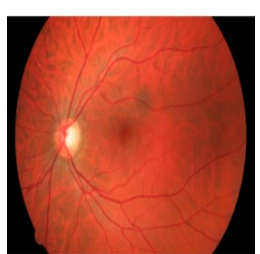

Normal Retina

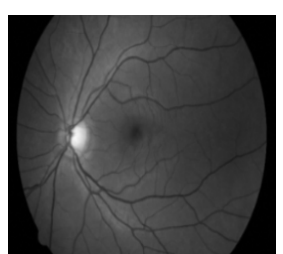

Green Channel

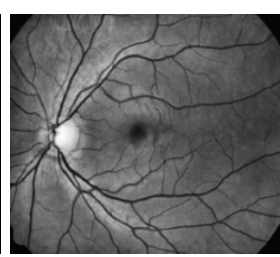

Enhanced Image
Figure 8. Pre-processed Image Samples

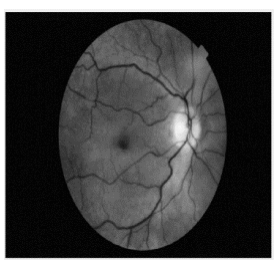

Pre-processed Image

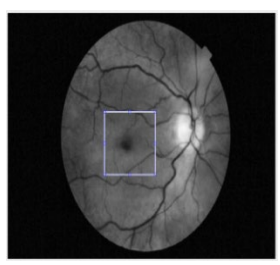

Bounding box for ROI

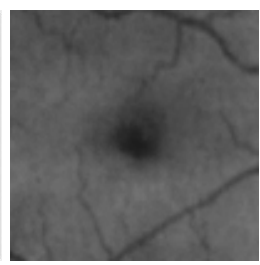

Segmented Macula
Figure 9. Segmentation Process

\subsection{Feature Extraction}

In the machine learning approach, it is very important to provide useful features to the classifier to classify images correctly. Here, we have used Local Binary Pattern (LBP) to extract features from the segmented macula region. LBP is a very efficient spatial domain texture operator that performs neighbourhood operations to convert image pixels into a binary value. It labels the pixels of an image by thresholding the neighbourhood of each pixel and considers the result as a binary number. Considering a pixel as a centre pixel, the neighbourhood of that centre pixel is counted as $\mathrm{N}$ number of neighbours within a radius of $\mathrm{R}$. It is a very powerful texture descriptor that detects all the possible edges in the image. With a $3 \times 3$ cell, the grey value of each pixel of the circular neighbourhood is computed. If the computed pixel values are greater than the centre pixel, the $\mathrm{N}$ neighbour pixels are set to the 1 otherwise set to 0 . For the centre pixel $p_{-} c$ and neighbouring pixel $\mathrm{p} \_\mathrm{n}$ with $\mathrm{N}$ neighbourhood, the equation of LBP can be calculated as follows [76,77]:

$$
L B P_{N R}=\sum_{N=0}^{N-1} s\left(p_{n}-p_{c}\right)
$$

Where,

$$
s(x)=\left\{\begin{array}{l}
1, \text { if } x \geq 0 \\
0, \text { if } x<0
\end{array}\right.
$$

In our work, we considered $\mathrm{N}=8$ and $\mathrm{R}=1$. After that, LBP features encode local texture information into $1 \times 59$ based on the computed histogram bin. That means a feature vector of 59 LBP features is generated. Fig. 10 shows the extracted LBP features for our segmented ROI, i.e. macula region.

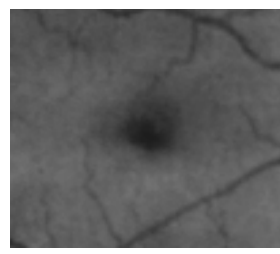

Segmented Image

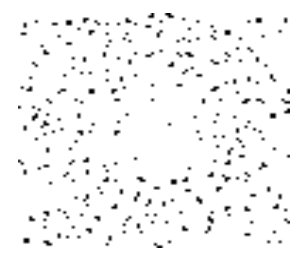

LBP Features

\section{Figure 10. LBP features}

\subsection{Classification}

For classifying abnormal and normal retina k-Nearest Neighbour (K-NN) algorithm is used. K-NN is a supervised classification algorithm which classifies a data point to a particular class based on the class of its neighboring data points. ' $\mathrm{K}$ ' is a parameter in the algorithm, which denotes the number of neighbors to consider while classifying a data point. The algorithm starts off with choosing suitable value of ' $\mathrm{K}$ '. Then we need to measure the distance between given data point and all other points in the dataset using suitable distance metric like Euclidean, Manhattan, etc. The ' $\mathrm{K}$ ' nearest point from the given point is found based upon their distances. Once ' $\mathrm{K}$ ' nearest neighbors are found, then the given data point falls in the class where the majority of the neighbors fall. This algorithm falls in the category of instance-based learning. Fig 11 explains how a new data is classified into a particular class based on $\mathrm{K}$ neighbors. 


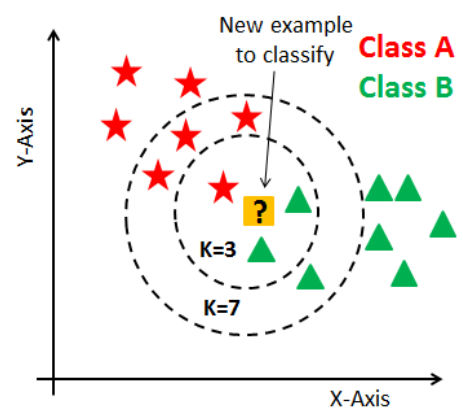

Figure 11. K-Nearest Neighbor Algorithm

\section{Experimental Analysis}

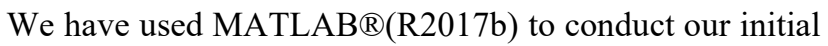
experiments. For the experiments, the images of different retinal images are collected from two publicly available databases, viz. STARE and Retinal Image Bank.

\subsection{Database Used:}

In this study, we have collected normal retina image along with the five target retinal diseases, viz., Diabetic Retinopathy, Diabetic Macular Edema, Retinal Vein Occlusion, Age-related Macular Degeneration, and Drusen from the following two publicly available databases.

1. STARE Database: The STARE (STructured Analysis of the Retina) Project was introduced by Michael Goldbaum, at the University of California, San Diego in 1975. It was funded by the U.S. National Institutes of Health. The STARE database contains 400 raw retina images size $700 \times 605$ and TIF format with diagnostic results. The images include normal retina to retina affected by various diseases such as Diabetic Retinopathy, Retinal Vein Occlusion, Coat's disease, Hypertensive Retinopathy, etc. [78]

2. The Retina Image Bank: It is a project from the American Society of Retina Specialists. Launched in August 2012. It contains 23,337 retina images with different diagnosis and all the images are of different size and format.

From both the databases, we have collected total 138 images of six categories (DR, DME, AMD, RVO, Drusen, and Normal).

\subsection{Experimental Results:}

After image pre-processing, segmentation, and LBP feature extraction, the features are fed to a k-Nearest Neighbour classifier. For training k-NN classifier, a total of 100 images are used. For a balanced training, 50 normal and 50 abnormal images are used. The 50 abnormal image set includes 10 images from each five target categories (DR, DME, AMD, RVO, and Drusen) of retinal abnormality. After training, the classifier is tested with 40 images, out of which 10 are normal images and 30 abnormal images. The details of the training and testing images are given in Table-5.

The performance of this method was evaluated in terms of Accuracy, Sensitivity, and Specificity. The accuracy measures the correct classification rate of the disease and in the initial experiment; the method has achieved $80.0 \%$ accuracy. Sensitivity measures the percentage of the people actually having the disease diagnosed correctly and the method achieved a sensitivity of $90.0 \%$. On the other hand, specificity measures the percentage of the people not having disease diagnosed correctly and the method has attained $76.7 \%$. Table-6 shows the performance of the system. Fig. 12 shows the confusion matrix of the classification. From the confusion matrix, it can be observed that, out of 40 test images, the classifier correctly classified 32 images into respective classes (Normal and Abnormal) and misclassified 8 images. The misclassification rate is $20 \%$, positive predictive value is $56.3 \%$ and negative predictive value is $95.8 \%$.

Discussion: The proposed method is just an initialization of the idea that for fast-track treatment to prevent vision loss, we can focus on the most important region of the retina. Since Macula is responsible for central vision, we particularly emphasized on the notion of detecting any abnormality near macula region. Most of the time people consult with the doctors or clinicians or ophthalmologists when the situation is already very bad or the disease progression has already started affecting the vision. In that situation, ophthalmologists mainly check how far the abnormalities have affected the macula region.

Table 5. Details of Training and Testing Images

\begin{tabular}{lll}
\hline Types of Images & $\begin{array}{l}\text { No. of Training } \\
\text { Images }\end{array}$ & $\begin{array}{l}\text { No. of Testing } \\
\text { Images }\end{array}$ \\
\hline DR & 10 & 10 \\
RVO & 10 & 5 \\
AMD & 10 & 7 \\
DME & 10 & 4 \\
Drusen & 10 & 4 \\
Normal & 50 & 10 \\
\hline & Total $=100$ & Total $=40$
\end{tabular}


Table 1. Performance Measures for the Proposed Method

\begin{tabular}{lll}
\hline Accuracy & Sensitivity & Specificity \\
\hline $80 \%$ & $90 \%$. & $76.7 \%$ \\
\hline
\end{tabular}

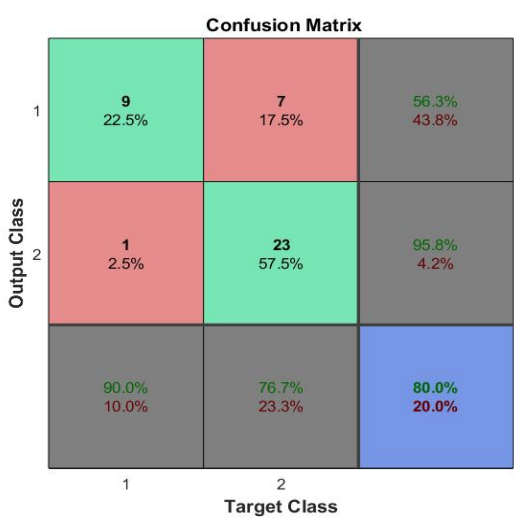

Fig 12. Confusion Matrix for classifying Normal and Abnormal Retinal image

Therefore, we would like to justify our contribution to this particular field. However, the proposed method is yet to be fully developed. The proposed method is kind of semi-automated as the segmentation of macula region is a manual process at this moment. Therefore, only the medical practitioners/ophthalmologists will be able to use this method for accurate ROI selection. The accuracy of the method can be improved with more training images. We can also use deep learning method, which is a very hot trend in medical image processing field, for better performance. Deep learning model such as Convolutional Neural Network (CNN) can significantly increase the classification accuracy and overall performance of the proposed method. However, one challenge in the deep learning models is the requirement of a large number of training datasets. Especially, in medical filed, it is difficult to get such large number of labelled dataset. Another drawback of deep learning models is that they are highly complex and carry extra computation burden. For this kind of medical application, which is meant for the use of healthcare clinics/hospitals, it is arguable to expect that they will be blessed with technologically advanced equipment, especially the rural health care centres or hospitals. Therefore, not necessarily deep learning will be an optimal solution in this case. An efficient automated macula segmentation method coupled with a simple machine learning classifier might also do the charm. In future, we will conduct more experiments on this to find the best, yet simple solution for retinal abnormality detection and prevent blindness.

\section{Conclusion}

In this paper, we have provided an extensive survey on the role of macular edema condition in various retinal diseases and how it is the prime cause of blindness. ME leads to the permanent vision loss starting from all retinal blood vascular diseases such as DR, RVO, AMD to postophthalmic surgical condition Cystoid Macular Edema (CME). We have also discussed the various state-of-theart automated methods for detection of various retinal blood vascular diseases, particularly, DR, RVO, DME, and AMD. We pointed out that most of the existing methods are disease-specific. We justified the notion that it will be beneficial to have a method that can analyse the macula region and alert if there is any abnormality near that region to prevent vision loss. To support the notion, we also proposed a simple method to detect retinal abnormality using colour fundus image. The proposed method is an initial experiment that uses a semiautomated macula segmentation method. Then, it automatically classifies the images into normal and abnormal using kNN classifier. The method has attained an accuracy of $79.2 \%$, sensitivity of $85.7 \%$, and specificity of $70 \%$. This project has a diverse future scope. The two main future prospects are: i) we can improve the performance using deep learning models or ii) we can find an optimized machine learning classifier coupled with accurate automated segmentation method to make it "ease of use" by all healthcare centres in both urban and rural areas

\section{References}

[1] Tah V, Orlans HO, Hyer J, Casswell E, Din N, Sri Shanmuganathan $\mathrm{V}$, et al. Anti-VEGF therapy and the retina: An update. J Ophthalmol 2015. https://doi.org/10.1155/2015/627674.

[2] Johnson MW. Etiology and Treatment of Macular Edema. Am J Ophthalmol 2009. https://doi.org/10.1016/j.ajo.2008.07.024.

[3] Ciulla TA, Amador AG, Zinman B. Diabetic retinopathy and diabetic macular edema: Pathophysiology, screening, and novel therapies. Diabetes Care 2003;26:2653-64. https://doi.org/10.2337/diacare.26.9.2653.

[4] Hykin P. Retinal Vein Occlusion (RVO) Guidelines. R Coll Ophthalmol 2015:4-35. https://doi.org/10.1016/j.ophtha.2015.10.045.

[5] Bhakta AS, Fortun J, Thomas J, Greer A, Kishor K, Maharaj A. Visually Significant Cystoid Macula Edema after Glaucoma Drainage Implant Surgery. J Glaucoma 2018;27:184-8. https://doi.org/10.1097/IJG.0000000000000855.

[6] Rotsos T. Cystoid macular edema. Clin Ophthalmol 2008;2:919. https://doi.org/10.2147/OPTH.S4033.

[7] Fardeau C, Champion E, Massamba N, Lehoang P. Uveitic macular edema. Eye 2016. https://doi.org/10.1038/eye.2016.115.

[8] Hamel C. Retinitis pigmentosa. Orphanet J Rare Dis 2006. https://doi.org/10.1186/1750-1172-1-40.

[9] Alli P. Retinal Image Analysis for Abnormality Detection- 
An Overview Department of CSE, PSNA College of Engineering and Technology Dindigul, Department of CSE , Velammal College of Engineering and Technology, Madurai , 2012;8:436-42.

[10] Bhutia KL. Prevalence Of Diabetic Retinopathy in Type 2 Diabetic Patients Attending Tertiary Care Hospital In Sikkim. Delhi J Ophthalmol 2017;28. https://doi.org/10.7869/djo.306.

[11] Bressler NM. Age-Related Macular Degeneration Is the Leading Cause of Blindness... J Am Med Assoc 2004;291:1900-1. https://doi.org/10.1001/jama.291.15.1900.

[12] Kessel L, Tendal B, Jørgensen KJ, Erngaard D, Flesner P, Andresen JL, et al. Post-cataract prevention of inflammation and macular edema by steroid and nonsteroidal anti-inflammatory eye drops: A systematic review. Ophthalmology

2014. https://doi.org/10.1016/j.ophtha.2014.04.035.

[13] Hayreh SS, Zimmerman B, McCarthy MJ, Podhajsky P. Systemic diseases associated with various types of retinal vein occlusion. Am J Ophthalmol 2001. https://doi.org/10.1016/S0002-9394(00)00709-1.

[14] McCluskey P, Powell PRJ. The eye in systemic inflammatory diseases. Lancet, 2004. https://doi.org/10.1016/S0140-6736(04)17554-5.

[15] Coscas G, Cunha-Vaz J, Soubrane G. Macular Edema: Definition and basic concepts. Dev Ophthalmol 2017;58:110. https://doi.org/10.1159/000455264.

[16] Bandello F, BattagliaParodi M, Lanzetta P. Diabetic macular edema n.d.;47:73-110.

[17] Finkelstein D. Ischemic Macular Edema Recognition and Favorable Natural History in Branch Vein Occlusion. Arch Ophthalmol 1992;110:1427-34. https://doi.org/10.1001/archopht.1992.01080220089028.

[18] Khayat M, Williams M, Lois N. Ischemic retinal vein occlusion: characterizing the more severe spectrum of retinal vein occlusion. Surv Ophthalmol 2018;63:816-50. https://doi.org/10.1016/J.SURVOPHTHAL.2018.04.005.

[19] Cheng J, Wong DWK, Cheng X, Liu J, Tan NM, Bhargava $\mathrm{M}$, et al. Early age-related macular degeneration detection by focal biologically inspired feature. Proc. - Int. Conf. Image Process. ICIP, 2012, p. 2805-8. https://doi.org/10.1109/ICIP.2012.6467482.

[20] Minnella AM, Savastano MC, Zinzanella G, Mazzone G, Federici M, Gari M, et al. Spectral-domain optical coherence tomography in irvine-gass syndrome. Retina 2012;32:581-7.

https://doi.org/10.1097/IAE.0b013e31821e2225.

[21] Munk MR, Jampol LM, Simader C, Huf W, Mittermüller TJ, Jaffe GJ, et al. Differentiation of diabetic macular edema from pseudophakic cystoid macular edema by spectral-domain optical coherence tomography. Investig Ophthalmol Vis Sci 2015;56:6724-33. https://doi.org/10.1167/iovs.15-17042.

[22] Dowler JGF, Sehmi KS, Hykin PG, Hamilton AMP. The natural history of macular edema after cataract surgery in diabetes. Ophthalmology 1999. https://doi.org/10.1016/S0161-6420(99)90148-3.

[23] Massa H, Pipis SY, Adewoyin T, Vergados A, Patra S, Panos GD. Macular edema associated with non-infectious uveitis: Pathophysiology, etiology, prevalence, impact and management challenges. Clin Ophthalmol 2019;13:1761-77. https://doi.org/10.2147/OPTH.S180580.

[24] Koronis S, Stavrakas P, Balidis M, Kozeis N, Tranos PG. Update in treatment of uveitic macular edema. Drug Des Devel Ther 2019;13:667-80. https://doi.org/10.2147/DDDT.S166092.
[25] Abramoff MD, Garvin MK, Sonka M. Retinal imaging and image analysis. IEEE Rev Biomed Eng 2010;3:169208. https://doi.org/10.1109/RBME.2010.2084567.

[26] Salz DA, Witkin AJ. Imaging in diabetic retinopathy. Middle East Afr J Ophthalmol 2015;22:145-50. https://doi.org/10.4103/0974-9233.151887.

[27] Besenczi R, Tóth J, Hajdu A. A review on automatic analysis techniques for color fundus photographs. Comput Struct Biotechnol J 2016;14:371-84. https://doi.org/10.1016/J.CSBJ.2016.10.001.

[28] Yannuzzi LA, Ober MD, Slakter JS, Spaide RF, Fisher YL, Flower RW, et al. Ophthalmic fundus imaging: Today and beyond. Am J Ophthalmol 2004. https://doi.org/10.1016/j.ajo.2003.12.035.

[29] Li LJ, Ikram MK, Wong TY. Retinal vascular imaging in early life: Insights into processes and risk of cardiovascular disease. J Physiol 2016. https://doi.org/10.1113/JP270947.

[30] Hern M, Engineering O, Polit OU, July C. Comprehensive Retinal Image Analysis : Image Processing and Feature Extraction Techniques Oriented to the Clinical Task 2013.

[31] Hassan T, Akram MU, Hassan B, Nasim A, Bazaz SA. Review of OCT and fundus images for detection of Macular Edema. IST 2015 - 2015 IEEE Int Conf Imaging Syst Tech Proc 2015:5-8. https://doi.org/10.1109/IST.2015.7294517.

[32] Virgili G, Menchini F, Casazza G, Hogg R, Rr D, Wang X, et al. Optical coherence tomography ( OCT ) for detection of macular oedema in patients with diabetic retinopathy ( Review ) 2015. https://doi.org/10.1002/14651858.CD008081.pub3.www.coc hranelibrary.com.

[33] Ali S, Sidibé D, Adal KM, Giancardo L, Chaum E, Karnowski TP, et al. Statistical atlas based exudate segmentation. Comput Med Imaging Graph 2013. https://doi.org/10.1016/j.compmedimag.2013.06.006

[34] Fleming AD, Philip S, Goatman KA, Olson JA, Sharp PF. Automated microaneurysm detection using local contrast normalization and local vessel detection. IEEE Trans Med Imaging 2006;25:1223-32. https://doi.org/10.1109/TMI.2006.879953.

[35] Jelinek HJ, Cree MJ, Worsley D, Luckie A, Nixon P. An automated microaneurysm detector as a tool for identification of diabetic retinopathy in rural optometric practice. Clin Exp Optom 2006;89:299-305. https://doi.org/10.1111/j.1444-0938.2006.00071.x.

[36] Sánchez CI, Mayo A, García M, López MI, Hornero R. Automatic Image Processing Algorithm to Detect Hard Exudates based on Mixture Models. Ieee 2006;1:4453-6.

[37] Sánchez CI, Hornero R, López MI, Aboy M, Poza J, Abásolo D. A novel automatic image processing algorithm for detection of hard exudates based on retinal image analysis. Med Eng Phys 2008. https://doi.org/10.1016/j.medengphy.2007.04.010.

[38] Jaafar HF, Nandi AK, Al-Nuaimy W. Decision support system for the detection and grading of hard exudates from color fundus photographs. J Biomed Opt 2011;16:116001. https://doi.org/10.1117/1.3643719.

[39] Sopharak A, Uyyanonvara B, Barman S, Williamson TH. Automatic detection of diabetic retinopathy exudates from non-dilated retinal images using mathematical morphology methods. Comput Med Imaging Graph 2008;32:720-7.

https://doi.org/10.1016/j.compmedimag.2008.08.009.

[40] Zhang X, Thibault G, Decencière E, Marcotegui B, Laÿ B, Danno R, et al. Exudate detection in color retinal 
images for mass screening of diabetic retinopathy. Med Image Anal 2014;18:1026-43. https://doi.org/10.1016/j.media.2014.05.004.

[41] Jaafar HF, Nandi AK, Al-Nuaimy W. Automated detection of red lesions from digital colour fundus photographs. Proc. Annu. Int. Conf. IEEE Eng. Med. Biol. Soc. EMBS,

2011 https://doi.org/10.1109/IEMBS.2011.6091539.

[42] Quellec G, Lamard M, Josselin PM, Cazuguel G, Cochener B, Roux C. Optimal Wavelet Transform for the Detection of Microaneurysms in Retina Photographs. IEEE Trans Med Imaging 2008;27:1230-41. https://doi.org/10.1109/TMI.2008.920619.

[43] García M, López MI, Álvarez D, Hornero R. Assessment of four neural network based classifiers to automatically detect red lesions in retinal images. Med Eng Phys 2010;32:1085-93. https://doi.org/10.1016/j.medengphy.2010.07.014.

[44] Zhang B, Wu X, You J, Li Q, Karray F. Detection of microaneurysms using multi-scale correlation coefficients. Pattern Recognit 2010;43:2237-48. https://doi.org/10.1016/j.patcog.2009.12.017.

[45] Lazar I, Hajdu A. Retinal microaneurysm detection through local rotating cross-section profile analysis. IEEE Trans Med Imaging 2013;32:400-7. https://doi.org/10.1109/TMI.2012.2228665.

[46] Singalavanija A, Supokavej J, Bamroongsuk P, Sinthanayothin C, Phoojaruenchanachai S, Kongbunkiat V. Feasibility study on computer-aided screening for diabetic retinopathy. Jpn J Ophthalmol 2006;50:361-6. https://doi.org/10.1007/s10384-005-0328-3.

[47] Tang HL, Goh J, Peto T, Ling BWK, Al turk LI, Hu $\mathrm{Y}$, et al. The Reading of Components of Diabetic Retinopathy: An Evolutionary Approach for Filtering Normal Digital Fundus Imaging in Screening and Population Based Studies. PLoS One 2013;8. https://doi.org/10.1371/journal.pone.0066730.

[48] Usman Akram M, Khalid S, Tariq A, Khan SA, Azam F. Detection and classification of retinal lesions for grading of diabetic retinopathy. Comput Biol Med 2014;45:161-71. https://doi.org/10.1016/j.compbiomed.2013.11.014.

[49] Dupas B, Walter T, Erginay A, Ordonez R, DebJoardar N, Gain P, et al. Evaluation of automated fundus photograph analysis algorithms for detecting microaneurysms, haemorrhages and exudates, and of a computer-assisted diagnostic system for grading diabetic retinopathy. Diabetes Metab 2010. https://doi.org/10.1016/j.diabet.2010.01.002.

[50] Mookiah MRK, Acharya UR, Martis RJ, Chua CK, Lim CM, Ng EYK, et al. Evolutionary algorithm based classifier parameter tuning for automatic diabetic retinopathy grading: A hybrid feature extraction approach. Knowledge-Based Syst 2013;39:9-22. https://doi.org/10.1016/j.knosys.2012.09.008.

[51] Fleming AD, Goatman KA, Philip S, Prescott GJ, Sharp PF, Olson JA. Automated grading for diabetic retinopathy: A large-scale audit using arbitration by clinical experts. $\mathrm{Br} \quad \mathrm{J} \quad$ Ophthalmol 2010. https://doi.org/10.1136/bjo.2009.176784.

[52] Soto-Pedre E, Navea A, Millan S, Hernaez-Ortega MC, Morales J, Desco MC, et al. Evaluation of automated image analysis software for the detection of diabetic retinopathy to reduce the ophthalmologists' workload. Acta Ophthalmol 2015. https://doi.org/10.1111/aos.12481.

[53] Sim DA, Keane PA, Tufail A, Egan CA, Aiello LP, Silva PS. Automated Retinal Image Analysis for Diabetic
Retinopathy in Telemedicine. Curr Diab Rep 2015. https://doi.org/10.1007/s11892-015-0577-6.

[54] Gulshan V, Peng L, Coram M, Stumpe MC, Wu D, Narayanaswamy A, et al. Development and Validation of a Deep Learning Algorithm for Detection of Diabetic Retinopathy in Retinal Fundus Photographs. JAMA 2016;316:2402-10. https://doi.org/10.1001/jama.2016.17216.

[55] Doshi D, Sheqoy A, Sidhpura D, Gharpure P. Diabetic Retinopathy Detection using Deep Convolutional Neural Networks. 2016 Int Conf Comput Anal Secur Trends 2016.

[56] Chandore Vishakha SA. Automatic Detection of Diabetic Retinopathy using deep Convolutional Neural Network. Ijar 2017;3:633-41.

[57] Abràmoff MD, Reinhardt JM, Russell SR, Folk JC, Mahajan VB, Niemeijer $M$, et al. Automated Early Detection of Diabetic Retinopathy. Ophthalmology 2010. https://doi.org/10.1016/j.ophtha.2010.03.046.

[58] Abràmoff $\mathrm{MD}$, Folk JC, Han DP, Walker JD, Williams DF, Russell SR, et al. Automated analysis of retinal images for detection of referable diabetic retinopathy. JAMA Ophthalmol 2013;131:351-7. https://doi.org/http://dx.doi.org/10.1001/jamaophthalmol.20 13.1743 .

[59] Sánchez CI, Niemeijer M, Dumitrescu A V., SuttorpSchulten MSA, Abràmoff MD, van Ginneken B. Evaluation of a Computer-Aided Diagnosis System for Diabetic Retinopathy Screening on Public Data. Investig Opthalmology Vis Sci 2011;52:4866. https://doi.org/10.1167/iovs.10-6633.

[60] Srinivasan PP, Kim LA, Mettu PS. Fully automated detection of diabetic macular edema and dry age-related macular degeneration from optical coherence tomography images 2014;5:3568-77.

[61] Sengar N, Dutta MK, Burget R, Povoda L. Detection of diabetic macular edema in retinal images using a region based method. 2015 38th Int. Conf. Telecommun. Signal Process. TSP 2015, Institute of Electrical and Electronics Engineers Inc.; 2015, p. 412-5. https://doi.org/10.1109/TSP.2015.7296294.

[62] Wang Y, Zhang Y, Yao Z, Zhao R, Zhou F. Machine learning based detection of age-related macular degeneration (AMD) and diabetic macular edema (DME) from optical coherence tomography (OCT) images. Biomed Opt Express 2016;7. https://doi.org/10.1364/boe.7.004928.

[63] Singh RK, Gorantla R. DMENet: Diabetic Macular Edema diagnosis using Hierarchical Ensemble of CNNs. PLoS One 2020;15:e0220677. https://doi.org/10.1371/journal.pone.0220677.

[64] Zhang H, Chen Z, Chi Z, Fu H. Hierarchical local binary pattern for branch retinal vein occlusion recognition with fluorescein angiography images. Electron Lett 2014;50:4-5. https://doi.org/10.1049/el.2014.2854.

[65] Anitha J, Selvathi D, Hemanth DJ. Neural Computing Based Abnormality Detection in Retinal Optical Images. 2009 IEEE Int Adv Comput Conf 2009:630-5. https://doi.org/10.1109/IADCC.2009.4809085.

[66] Fazekas Z, Hajdu A, Lázár I, Kovács G, Csákány B, Calugaru DM, et al. Influence of Using Different Segmentation Methods on the Fractal Properties of the Identified Retinal Vascular Networks in Healthy Retinas and in Retinas with Vein Occlusion. Proc KÉPAF 2015 2015:360-73.

[67] Zode JJ. Detection of Branch Retinal Vein Occlusion using Fractal Analysis 2017;162:28-32.

[68] Gayathri R, Vijayan R, Prakash JS, Chandran NS. 
CLBP for Retinal Vascular Occlusion Detection 2014;11:204-9.

[69] Zhao R, Chen Z, Chi Z. Convolutional Neural Networks for Branch Retinal Vein Occlusion recognition?, 2015 IEEE Int Conf Inf Autom 2015:1633-6. https://doi.org/10.1109/ICInfA.2015.7279547.

[70] Choudhury B., Then P.H.H. R V. Automatic Detection Of Retinal Vein Occlusion ( RVO ) Using Convolutional Neural Network ( CNN ). Big Data Vis Anal Springer, Cham 2017:1-21.

[71] Agurto C, Simon Barriga E, Murray V, Nemeth S, Crammer R, Bauman $\mathrm{W}$, et al. Automatic detection of diabetic retinopathy and age-related macular degeneration in digital fundus images. Investig Ophthalmol Vis Sci 2011;52:5862-71. https://doi.org/10.1167/iovs.10-7075.

[72] Garnier M, Hurtut $T$, Ben Tahar H, Cheriet F. Automatic multiresolution age-related macular degeneration detection from fundus images. Med Imaging 2014 Comput Diagnosis 2014;9035:903532. https://doi.org/10.1117/12.2043099.

[73] Burlina P, Freund DE, Joshi N, Wolfson Y, Bressler NM. Detection of age-related macular degeneration via deep learning. Proc. - Int. Symp. Biomed. Imaging, vol. 2016June, IEEE Computer Society; 2016, p. 184-8. https://doi.org/10.1109/ISBI.2016.7493240.

[74] Tan JH, Bhandary S V., Sivaprasad S, Hagiwara Y, Bagchi A, Raghavendra U, et al. Age-related Macular Degeneration detection using deep convolutional neural network. Futur Gener Comput Syst 2018;87:127-35. https://doi.org/10.1016/j.future.2018.05.001.

[75] Choudhury B, Then PHH, Raman V. Automated detection of central retinal vein occlusion using convolutional neural network. 2018. https://doi.org/10.1007/978-3-319-63917-8_1.

[76] Ojala T, Pietikäinen M, Mäenpää T. Multiresolution gray-scale and rotation invariant texture classification with local binary patterns. IEEE Trans Pattern Anal Mach Intell 2002;24:971-87. https://doi.org/10.1109/TPAMI.2002.1017623.

[77] Malhotra A, Sankaran A, Mittal A, Vatsa M, Singh R. Fingerphoto authentication using smartphone camera captured under varying environmental conditions. Hum. Recognit. Unconstrained Environ. Using Comput. Vision, Pattern Recognit. Mach. Learn. Methods Biometrics, Elsevier; 2017, p. 119-44. https://doi.org/10.1016/B978-008-100705-1.00006-3.

[78] Hoover A, Goldbaum M. Locating the optic nerve in a retinal image using the fuzzy convergence of the blood vessels. IEEE Trans Med Imaging 2003;22:951-8. https://doi.org/10.1109/TMI.2003.815900. 